\title{
PCR fingerprinting microbes by random amplification of polymorphic DNA
}

Technical simplicity combined with sensitivity and speed generated interest in the application of the polymerase chain reaction (PCR) to the diagnosis of infectious diseases. Now these same merits have led to the development of a PCR-based typing system. Initially this involved amplification between paired primers derived from previously characterised sequences. For example, a rapid method of fingerprinting cytomegalovirus (CMV) was developed by amplifying the hypervariable L-S junction region by PCR between consensus oligonucleotide primers to produce strain-specific variably sized PCR products. ${ }^{1}$ The PCR products were detected by gel electrophoresis and Southern blot hybridisation against a ${ }^{32} \mathrm{P}$-labelled CMV junctional fragment. The PCR profiles obtained were unique for unrelated strains whereas similar patterns were observed for epidemiologically related strains isolated from members of the same family. In some studies, such as that carried out on human herpes virus 6 with primers from known viral DNA sequences, the amplified products were analysed by a combination of Southern blot hybridisation, digestion with restriction endonucleases and partial nucleotide sequencing. ${ }^{2}$

For many organisms genetic maps are not available and relatively little is known of their molecular biology. In such situations the DNA markers most commonly used have been restriction fragment length polymorphisms (RFLPs). Fragments are usually generated by frequent-cutting enzymes and separated by conventional agarose gel electrophoresis, but occasionally rare-cutting enzymes are used and larger fragments are separated by pulsed-field gel electrophoresis. RFLPs have been used successfully to generate numerous microbial typing systems, but for some organisms discrimination is suboptimal because there is a tendency for one or two genetic types to predominate amongst an apparently heterogeneous population. ${ }^{3}$ Better discrimination between isolates can be achieved by the secondary step of Southern blot hybridisation with radiolabelled probes recognising repetitive DNA sequences. However, this adds a rather laborious, expensive second step which is incompatible with large scale epidemiological studies.

Recently, an alternative DNA polymorphism assay has been established, based on the amplification of genomic DNA with a single primer of arbitrary nucleotide sequence. ${ }^{4,5}$ The PCR is carried out at low annealing temperatures $\left(36^{\circ} \mathrm{C}\right)$ under conditions that favour relatively non-specific binding of the primer to multiple sites of the template DNA. This then results in multiple PCR products which are separated out according to size by conventional agarose gel electrophoresis. These polymorphisms have been termed RAPD markers, ${ }^{4}$ after random amplified polymorphic DNA, or arbitrary primed PCR (AP-PCR). ${ }^{5}$ Unlike PCR fingerprinting based on amplification of a specific gene, RAPD requires no sequence information and it scans the whole genome rather than relying on hypervariability within one specific gene. Each primer gives a different pattern of PCR products, each with the potential of detecting polymorphisms between strains. Therefore, discrimination between isolates can be maximised by combining the RAPD results obtained with several primers. Some primers may not generate polymorphic patterns with a particular microbe or they may generate a conserved PCR profile that is species-specific. DNA polymorphisms amplified with primers of nine nucleotides in length or longer result in relatively few amplification products, which on gel electrophoresis give rise to simple fingerprint patterns. With arbitrary primers as short as five nucleotides in length, more detailed and complex DNA profiles are generated which are usually resolved by polyacrylamide gel electrophoresis and silver staining rather than agarose gel electrophoresis visualised by ethidium bromide. $^{6}$ Another variation is to use two short arbitrary primers in combination for each PCR instead of separately. ${ }^{7}$ In the latter study, primer annealing was performed at temperatures as low as $30^{\circ} \mathrm{C}$ and amplification products were separated on agarose $1.5 \%$ gels.

RAPD typing has been applied successfully to the genetic fingerprinting of $\operatorname{man},{ }^{4}$ crops such as soyabean, ${ }^{4}$ rice $^{5}$ and banana, ${ }^{7}$ and bacteria including staphylococci and Streptococcus phytogenes. ${ }^{5}$ The method has been applied to two fungal plant pathogens, Fusarium solari ${ }^{8}$ and Leptospira maculens. ${ }^{9}$ We have found this technique particularly useful when applied to typing fungal pathogens, namely Candida albicans, Aspergillus fumigatus and Cryptococcus neoformans. All isolates are typable and reproducibility is comparable to RFLP. Discrimination tends to be considerably better than that obtained by RFLP analysis with frequent-cutting enzymes such as EcoRI. One particular primer generated 11 distinct fingerprints with 15 isolates of $C$. albicans, ${ }^{10}$ six fingerprints with 20 isolates of $A$. fumigatus ${ }^{11}$ and 12 fingerprints 
with 12 isolates of $C r$. neoformans. ${ }^{12}$ The simplicity, versatility and economy of RAPD-based typing systems make them an ideal means of genetically fingerprinting isolates, suitable for large scale epidemiological studies of these fungi. Whether it will

\section{References}

1. Sokol DM, Demmler GJ, Buffone GJ. Rapid epidemiologic analysis of cytomegalovirus by using polymerase chain reaction amplification of the L-S junction region. $J$ Clin Microbiol 1992; 30: 839-844.

2. Aubin JT, Collandre J, Candotti D et al. Several groups among human herpesvirus 6 strains can be distinguished by southern blotting and polymerase chain reaction. $J$ Clin Microbiol 1991; 29: 367-372.

3. Matthews RC, Burnie JP. The rapid identification of outbreaks of systemic candidosis by DNA fingerprinting. $B M J 1989$; 298: 354-357.

4. William JGK, Kubelik AR, Livak KJ, Rafalski JA, Tingey SV DNA polymorphisms amplified by arbitrary primers are useful as genetic markers. Nucleic Acids Res 1990; 18 6531-6535.

5. Welsh J, McClelland M. Fingerprinting genomes using PCR with arbitrary primers. Nucleic Acids Res 1990; 18 7213-7218.

6. Caetano-Anolles G, Bassam BJ, Gresshoff PM. DNA amplification fingerprinting using very short arbitrary oligonucleotide primers. Biotechnology 1991; 9: 553-556. prove to be equally valuable for typing other microbes is the subject of further investigation.

R. C. Matthews

Department of Medical Microbiology, University of Manchester Medical School, Oxford Road, Manchester M13 9PT.

7. Kaemmer D, Afza $R$, Weising $K$, Kahl G, Novak FJ. Oligonucleotide and amplification fingerprinting of wild species and cultivars of banana (Musa spp.). Biotechnology 1992; 10: 1030-1035.

8. Crowhurst RN, Hawthorne BT, Rikkerink EHA, Templeton MD. Differentiation of Fusarium solari f.sp. cucurbitae races 1 and 2 by random amplification of polymorphic DNA. Curr Genet 1991; 20: 391-396.

9. Goodwin PH, Annis SL. Rapid identification of genetic variation and pathotype of Leptosphaeria maculans by random amplified polymorphic DNA assay. Appl Environ Microbiol 1991; 57: 2482-2486.

10. Bostock A, Khettak MN, Matthews RC, Burnie JP. Comparison of PCR fingerprinting by random amplification of polymorphic DNA, with other molecular typing methods for Candida albicans. J Gen Microbiol 1993 (in press).

11. London K, Burnie JP, Coke A, Matthews RC. Application of polymerase chain reaction to fingerprinting Aspergillus funigatus by random amplification of polymorphic DNA. $J$ Clin Micro 1993; 31 : 1117-1121.

12. Crampin AC, Matthews RC. PCR fingerprinting Cryptococcus neoformans by random amplification of polymorphic DNA. J Med Vet Mycol 1993 (in press). 